ORIGINAL ARTICLE

\title{
Early Outcomes of Laparoscopic Sleeve Gastrectomy (LSG) in Morbidly Obese Patients
}

\author{
RAHMAT ULLAH SHAH ${ }^{1}$, ADNAN BADAR ${ }^{2}$, HAFIZ NIAMAT ULLAH ${ }^{3}$, SADIA SHAH ${ }^{4}$, SHEIKH MUHAMMAD IBQAR \\ AZEEM ${ }^{5}$, AFTAB HUSSAIN ${ }^{6}$ \\ ${ }^{1}$ Assistant Professor, Department of Surgery, Lady Reading Hospital Peshawar \\ ${ }^{2}$ Assistant Professor, Department of Anatomy, Saidu Medical College, Swat \\ ${ }^{3}$ Assistant Professor, Department of Surgery, Lady Reading Hospital, Peshawar \\ ${ }^{4}$ Assistant Professor, Department of Surgery, Kuwait Teaching Hospital/ Peshawar Medical College, Peshawar \\ ${ }^{5}$ Assistant Professor, Department of Surgery, Peshawar Medical College, Peshawar \\ ${ }^{6}$ Senior Registrar, Department of Surgery, Peshawar Medical College, Peshawar \\ Corresponding Author: Dr. Hafiz Niamat Ullah, Email: niamatsurgeon@yahoo.com
}

\begin{abstract}
Objective: To determine the early outcomes of laparoscopic sleeve gastrectomy with respect to weight loss and amelioration of comorbid conditions in morbidly obese patients.

Study Design: Prospective descriptive study.

Place and Duration of Study: MTI-Lady Reading hospital Peshawar and Royal Imperial hospital Swat from January 2018 to January 2020.

Materials and Methods: Total thirty-eight morbidly obese patients of either sex with age range of 25-65 years were included in this study. Informed written consent was taken from all the patients and their demographic details such as age, sex and comorbid conditions were recorded. All the patients underwent laparoscopic sleeve gastrectomy. Preoperative and postoperative data such as body mass index, total \& excess weight loss and impact on comorbidities were analyzed. Bariatric Analysis and Reporting Outcome System (BAROS) scoring system was used to analyze the outcomes. Follow-up was taken at 1 year post-operatively.

Results: Majority were female $25(65.8 \%)$ patients and $13(34.2 \%)$ males with mean age of $45.39 \pm 9.64$ years. Comorbidities such as hypertension, diabetes mellitus, hyperlipidemia and obstructive sleep apnoea were recorded in $13.2 \%, 26.3 \%, 7.9 \%$ and $10.53 \%$ patients respectively. Mean excess body weight loss (EWL) was $60.25 \pm 12.7 \mathrm{~kg}$ and mean body mass index loss was $15.14 \pm 9.33 \mathrm{~kg} / \mathrm{m}^{2}$ at 1 year follow up. Postoperative systolic blood pressure improvement was observed in $23(60.5 \%)$ patients. A significant improvement was observed regarding diabetes mellitus (preoperatively mean $\mathrm{HbA} 1 \mathrm{C} 9.7 \pm 5.9$ vs postoperatively mean $\mathrm{HbA1C} 4.42 \pm 3.6$ ) $\mathrm{p}$ value $<0.001$. According to the BAROS score, 5 (13.3\%) showed excellent, $14(36.8 \%)$ showed very good, 17 $(44.74 \%)$ showed good, 2 (5.3\%) showed fair and no patient showed poor outcomes. Satisfaction rate among patients was $94.7 \%$.

Conclusion: Laparoscopic sleeve gastrectomy is an excellent procedure both in terms of weight loss and amelioration of comorbid conditions in morbidly obese patients.

Key words: Sleeve gastrectomy, Laparoscopic, Excess body weight loss, Morbid obesity.
\end{abstract}

\section{INTRODUCTION}

There is a rising incidence of obesity across the globe. If the current trend continues, it is anticipated that 40 percent of the US population will be obese by 2025. Similarly, every fourth Pakistani adult is either obese or overweight and hence at a higher risk of suffering from obesity-related comorbid conditions. [1,2]Over 20 percent of children and adolescents have a body mass index $(\mathrm{BMI})>85$ percentile, which is a worrisome sign of the obesity epidemic's impact on public health[3]. Due to the obesity pandemic, there has been a revived interest in surgical treatment of morbid obesity, as well as in the application of laparoscopic techniques to bariatric surgery in the last few years. A successful weight loss, treatment of comorbidities, and admirable short- and long-term results are obtained with bariatric surgery[4-6]. It also decreased the overall mortality and provided a significant survival advantage $[7,8]$. The outcomes of laparoscopic sleeve gastrectomyin terms of weight loss and resolution of comorbid conditions associated with obesity are similar to gastric bypass procedure.[9]

To reduce morbidity and mortality in high-risk patients, especially super-super obese $(\mathrm{BMl}>60 \mathrm{~kg} / \mathrm{m} 2)$, sleeve gastrectomy was traditionally performed as the first stage of a 2-stage bariatric treatment. Biliopancreatic diversion with duodenal switch (BPD/DS) is another malabsorptive bariatric operation that uses LSG as the gastric component. [10]

Like other bariatric procedures, LSG also results in considerable and sustainable reduction in ghrelin hormones levels in the blood which is responsible for achieving good outcomes. Though not reversible LSG can be converted to a Roux-en-Y gastric bypass or BPD/DS.[11] As a single-step procedure in the surgical treatment of morbid obesity, LSG has demonstrated encouraging outcomes and is now a well-recognized procedure to treat obesity.[12]

For morbidly obese patients, it is a viable alternative because it is easily reproducible with low complications rate.13

Approximately the past 50 years, obesity in the United States has increased at an alarming rate, with over 98.7 million Americans affected. According to the Center for Disease Control and Prevention, obesity and associated co-morbidities accounted for 14.3 percent of health care spending in 2014. [14,15] In the treatment of obesity, 
weight loss surgery is believed to be a safe and permanent alternative. The techniques that are used are always changing and producing fabulous results.

Weight loss and resolution of obesity-related comorbidities were examined in the current study.

\section{MATERIALS AND METHODS}

This prospective descriptive study was conducted at MTILady Reading hospital Peshawar and Royal Imperial hospital Swat from January 2018 to January 2020.There were thirty-eight patients with BMI of more than 40 , or more than 35 with obesity-related comorbid diseases of both genders who were included. Patient's ages were ranging from 25 to 65 years. Demographic details like age and sex, and medical history was recorded after taking informed written consent from all the patients. Patients with severe gastric disorders, patients with previous history of bariatric surgery and those who were not interested to participate were excluded. All the patients had laparoscopic sleeve gastrectomy performed by two surgeons with similar experience. The bipolar ligasure was used for greater curvature gastrolysis and gastric resection was done over a $36 \mathrm{Fr}$ bougie, starting about $4 \mathrm{~cm}$ proximal to the pyloric ring. Imbrication of proximal staple line was done using $2 / 0$ $\mathrm{V}$-lock suture and leak test was done using methylene-blue dye at the end of each procedure. Preoperative and postoperative data such as body mass index, weight loss, comorbidities were analyzed. BAROS scoring system was used to analyze the outcomes. Follow-up was taken at 1 year post-operatively. All the data was analyzed using SPSS 24. P-value $<0.05$ was set as significant.

\section{RESULTS}

Majority were female $25(65.8 \%)$ patients and $13(34.2 \%)$ males with mean age of $45.39 \pm 9.64$ years. Co-morbidities such as hypertension, diabetes mellitus, hyperlipidemia and obstructive sleep apnea were recorded in $13.2 \%$, $26.3 \%, 7.9 \%$ and $10.53 \%$ patients respectively (Table 1 ).

Preoperative mean value of weight was recorded as $119.55 \pm 30.72 \mathrm{~kg}$ and postoperative findings of weight at 1 year was $80.9 \pm 22.4 \mathrm{~kg}$ with mean difference of $38.35 \pm 8.32$ $\mathrm{kg}$ at 1 year. Pre and postoperative findings regarding Body mass index were noted as $45.66 \pm 12.40 \mathrm{~kg} / \mathrm{m}^{2}$ and $30.42 \pm 3.34 \mathrm{~kg} / \mathrm{m}^{2}$ with mean difference of $15.14 \pm 9.33$ $\mathrm{kg} / \mathrm{m}^{2}$ at 1 year. Preoperative mean Excess weight was $70.34 \pm 25.42 \mathrm{~kg}$ and post-operative after 1 year the mean Excess weight loss (EWL) was $60.25 \pm 12.7 \mathrm{~kg}$. Postoperative percent EWL at 1 year was mean $72.42 \pm 13.7$ (Table 2).

Postoperative systolic blood pressure improvement from $145 \pm 17.41$ to $130 \pm 14.25(p<0.005)$ was observed in $23(60.5 \%)$ patients. A significant improvement was observed regarding diabetes mellitus (preoperatively mean $\mathrm{HbA} 1 \mathrm{C} 9.7 \pm 5.9$ vs postoperatively mean $\mathrm{HbA} 1 \mathrm{C} 4.42 \pm 3.6$ ) p-value $<0.001$. (Table 3 ). Hyperlipidemia and sleep apnea observed in 3 and 4 patients respectively, resolved in all patients postoperatively at 1 year (100\%).

According to the BAROS score, 5 (13.3\%) showed excellent, 14 (36.8\%) showed very good, 17 (44.74\%) showed good, 2 (5.3\%) showed fair and no patient showed poor outcomes. (Table 4). Satisfaction rate among patients was $94.7 \%$. (Table 5 )

\section{DISCUSSION}

After being performed for the first time in 1999, LSG as a stand-alone surgical procedure for obesity has been described since $2005^{15}$, and represents a rapidly emerging technique in the armamentarium of bariatric surgery. It is technically easier to perform than other types of bariatric surgery but has comparable outcomes. [16] The present study was conducted aimed to examine the outcomes of laparoscopic sleeve gastrectomy in patients presented with morbid obesity.

Table 1: Demographical information of the patients
\begin{tabular}{|l|l|l|}
\hline Variable & No. & $\%$ \\
\hline Age (years) & $45.39 \pm 9.64$ \\
\hline Gender & 13 & 34.2 \\
\hline Male & 25 & 64.8 \\
\hline Female & 5 & 13.2 \\
\hline Comorbidities & 10 & $26.3 \%$, \\
\hline Hypertension & 3 & $7.9 \%$ \\
\hline Diabetes mellitus & 4 & 10.53 \\
\hline Hyperlipidemia & \\
\hline Obstructive sleep apnea & 4 & \\
\hline
\end{tabular}

Table 2: Pre and postoperative at 1-yearfindings regarding weight, BMI and excess weight loss

\begin{tabular}{|c|c|c|c|c|}
\hline Variable & Pre-operative & Postoperative at 1 year & Difference & P-value \\
\hline Weight $(\mathrm{Kg})$ & $119.55 \pm 30.72$ & $80.9 \pm 22.4$ & $38.35 \pm 8.32$ & 0.0001 \\
\hline $\mathrm{BMI} \mathrm{Kg/m}$ & $45.66 \pm 12.40$ & $30.42 \pm 3.34$ & $15.14 \pm 9.33$ & 0.0001 \\
\hline Excess weight & $70.34 \pm 25.42$ & $19.09 \pm 7.68$ & $51.25 \pm 12.7$ & 0.0001 \\
\hline$\%$ Excess weight loss & - & $72.42 \pm 13.7$ & - & - \\
\hline \multicolumn{5}{|c|}{ able 3: Preoperative anc } \\
\hline Systolic BP & $145 \pm 17.41$ & $130 \pm 14.25$ & $15 \pm 3.16$ & 0.003 \\
\hline Diastolic BP & $80 \pm 10.15$ & $77 \pm 11.20$ & $4.0 \pm 10.35$ & 0.523 \\
\hline $\mathrm{HbA1c}$ & $9.7 \pm 5.9$ & $4.42 \pm 3.6$ & $5.28 \pm 2.3$ & 0.001 \\
\hline
\end{tabular}

Table 4: BAROS findings at 1 year Follow-up

\begin{tabular}{|l|l|l|}
\hline BAROS & No. & $\%$ \\
\hline Excellent & 5 & 13.3 \\
\hline Very Good & 14 & 36.8 \\
\hline Good & 17 & 14.74 \\
\hline Fair & 2 & 5.3 \\
\hline Poor & - & - \\
\hline
\end{tabular}

Table 5: Satisfaction rate at 1 years follow up

\begin{tabular}{|l|l|l|}
\hline Satisfaction & No. & $\%$ \\
\hline Yes & 36 & 94.7 \\
\hline No & 2 & 5.3 \\
\hline
\end{tabular}

In this study a total 38 patients of both genders were presented. Majority of the patients $64.8 \%$ were females. In their study no patient was below 25 years. The mean age 
of the patients in our study was $45.39 \pm 9.64$ years with age ranges 25 to 65 years. Many of studies reported similar patient's gender and ages were ranging 18 to 65 years.[17,18]

In our study, we found diabetes mellitus was the most frequent co-morbidity $26.3 \%$ followed by depression, hypertension and obstructive sleep apnea. [19,20] In present study we found preoperative mean value of weight was recorded as $119.55 \pm 30.72 \mathrm{~kg}$ and postoperative findings of weight at 1 year was $80.9 \pm 22.4 \mathrm{~kg}$ with mean difference of $38.35 \pm 8.32 \mathrm{~kg}$ at 1 year $p$-value 0.0001 . These results showed similarity to many other studies in which the authors reported the significant difference regarding weight observed in patients treated with laparoscopic sleeve gastrectomy for morbid obesity.[21,22]

The pre and postoperative findings regarding body mass index in our study were $45.66 \pm 12.40 \mathrm{~kg} / \mathrm{m}^{2}$ and $30.42 \pm 3.34 \mathrm{~kg} / \mathrm{m}^{2}$ with mean difference of $15.14 \pm 9.33$ $\mathrm{kg} / \mathrm{m}^{2}$ at 1 year. Preoperative mean Excess weight was70.34 $\pm 25.42 \mathrm{~kg}$ and post-operative mean EWL after 1 year was $51.25 \pm 12.7 \mathrm{~kg}$. Post-operative mean percent EWL at 1 year was $72.42 \pm 13.7$. These results showed similarity to several studies in which the statistically significant difference was observed regarding Excess body weight loss and BMI p-value $<0.05 .[23,24]$

In present study, we found postoperative systolic blood pressure improvement from $145 \pm 17.41$ to $130_{ \pm}$ $14.25(p<0.005)$ was observed in $23(60.5 \%)$ patients. $\bar{A}$ significant improvement was observed regarding diabetes mellitus (preoperatively mean $\mathrm{HbA} 1 \mathrm{C} \quad 9.7 \pm 5.9$ vs postoperatively mean $\mathrm{HbA1C} 4.42 \pm 3.6)$ p-value $<0.001$. (Table 3).

Hyperlipidemia and sleep apnea observed in 3 and 4 patients respectively, resolved in all patients postoperatively at 1 year (100\%). Although number of patients in our study were low but other studies also report an improvement/resolution of these comorbidities with LSG. $[9,25]$

According to the BAROS score, $5(13.3 \%)$ showed excellent, 14 (36.8\%) showed very good, 17 (44.74\%) showed good, 2 (5.3\%) showed fair and no patient showed poor outcomes. Many of previous study demonstrated the significant improvement regarding systolic blood pressure and the better outcomes regarding procedure at final follow-up.[26] In current study satisfaction rate among patients was $94.7 \%$.

\section{CONCLUSION}

Laparoscopic sleeve gastrectomy is an excellent procedure both in terms of weight loss and amelioration of comorbid conditions in morbidly obese patients. Our data is small but among initial few studies done in any tertiary care government hospital in Pakistan. Larger studies with comparisons to its counterpart are suggested to make recommendations for local ethnic population.

\section{REFERENCES}

1. Butt F, Farooq Butt A, Alam F, Aslam N, Abdul Moeed H, Butt FA Perception and Management of Obesity Among Pakistani Doctors. Cureus. 2019;11(2):e4156.Published 2019 Feb 28. doi:10.7759/cureus.4156

2. Kopelman, P. Obesity as a medical problem. Nature 404, 635643(2000). https://doi.org/10.1038/35007508
3. Hoppin AG. Obesity and the liver: developmental perspectives. Semin Liver Dis. 2004;24:381-387.

4. Buchwald $\mathrm{H}$, Avidor $\mathrm{Y}$, Braunwald $\mathrm{E}$, Jensen MD, Pories W, Fahrbach K, Schoelles K. Bariatric surgery: a systematic reviewandmetaanalysis.JAMA. 2004;292:1724-1737.

5. Maggard MA, Shugarman LR, Suttorp M, Maglione M, Sugerman HJ, Livingston EH, Nguyen NT, Li Z, Mojica WA, Hilton L, et al. Metaanalysis: surgical treatment of obesity. Ann Intern Med. 2005;142:547559.

6. Sugerman HJ, Kral JG. Evidence-based medicine reports on obesity surgery: a critique. Int J Obes (Lond) 2005;29:735-745.

7. Christou NV, Sampalis JS, Liberman M, Look D, Auger S, McLean AP MacLean LD. Surgery decreases long-term mortality, morbidity, and health care use in morbidly obese patients. Ann Surg. 2004;240:416423; discussion 423-424.

8. Flum DR, Dellinger EP. Impact of gastric bypass operation on survival: a population-based analysis. J Am Coll Surg. 2004;199:543-551.

9. Kikkas, E M; Sillakivi, T; Suumann, J; Kirsimägi, Ü; Tikk, T; Värk, P R (2019). Five-Year Outcome of Laparoscopic Sleeve Gastrectomy, Resolution of Comorbidities, and Risk for Cumulative Nutritional Deficiencies. Scandinavian Journal of Surgery, 108 (1), 10-16. DOI: $10.1177 / 1457496918783723$.

10. Gumbs AA, Gagner M, Dakin G, Pomp A. Sleeve gastrectomy for morbid obesity. Obes Surg. 2007; 17: 962-969

11. Langer FB, Reza Hoda MA, Bohdjalian A, et al. Sleeve gastrectomy and gastric banding: effects on plasma ghrelin levels. Obes Surg. 2005; 15: 1024-1029

12. ASMBS Clinical Issues Committee. Updated position statement on sleeve gastrectomy as a bariatric procedure. SurgObesRelat Dis2012; 8:e21-6.)

13. English WJ, DeMaria EJ, Brethauer SA, Mattar SG, Rosenthal RJ, Morton JM. American Society for Metabolic and Bariatric Surgery estimation of metabolic and bariatric procedures performed in the United States in 2016. SurgObesRelat Dis 2018;14:259-63.

14. Topart P, Becouarn G, Ritz P. Should biliopancreatic diversion with duodenal switch be done as single-stage procedure in patients with $\mathrm{BMI}>$ or $=50 \mathrm{~kg} / \mathrm{m} 2$ ? SurgObesRelat Dis. 2010 Jan-Feb;6(1):59-63.

15. Imes CC, Burke LE. The obesity epidemic: the United States as a cautionary tale for the rest of the world. CurrEpidemiol Rep. 2014:1(2):82-8.

16. Gloy VL, Briel M, Bhatt DL, et al. Bariatric surgery versus non-surgical treatment for obesity: a systematic review and meta-analysis of randomised controlled trials. BMJ. 2013;347:f5934.

17. Iannelli A, Dainese $R$, Piche $T$, Facchiano E, Gugenheim J. Laparoscopic sleeve gastrectomy for morbid obesity. World $J$ Gastroenterol. 2008;14(6):821-827. doi:10.3748/wjg.14.821

18. Zhang, Y., Zhu, C., Wen, X. et al. Laparoscopic sleeve gastrectomy improves body composition and alleviates insulin resistance in obesity related acanthosis nigricans. Lipids Health Dis 16, 209 (2017).

19. Khoraki J, Katz MG, Funk LM, Campos GM, et al. Feasibility and outcomes of laparoscopic sleeve gastrectomy after solid organ transplantation. SurgObesRelat Dis. 2016;12(1):75-83.

20. Young MT, Gebhart A, Phelan MJ, et al. Use and outcomes of laparoscopic sleeve gastrectomy vs laparoscopic gastric bypass: analysis of the American College of Surgeons NSQIP. J Am Coll Surg. 2015;220(5):880-5

21. AIEnazi, N.A., Ahmad, K.S., Elsamahy, I.A. et al. Feasibility and impact of laparoscopic sleeve gastrectomy after renal transplantation on comorbidities, graft function and quality of life. BMC Surg 21, 235 (2021).

22. Jakob T, Cal P, Deluca L, et al. Shorter than 24-h hospital stay for sleeve gastrectomy is safe and feasible. SurgEndosc. 2016;30(12):5596-600

23. Wang X, Chang XS, Gao L, et al. Effectiveness of laparoscopic sleeve gastrectomy for weight loss and obesity-associated co-morbidities: a 3-year outcome from mainland Chinese patients. SurgObesRelat Dis. 2016;12(7):1305

24. Vidal P, Ramón JM, Goday A, et al. Laparoscopic gastric bypass versus laparoscopic sleeve gastrectomy as a definitive surgical procedure for morbid obesity. Mid-term results. Obes Surg. 2013;23(3):292-9

25. D'Hondt M, Vanneste S, Pottel $H$ et al: Laparoscopic sleevegastrectomy as a single-stage procedure for the treatment ofmorbid obesity and the resulting quality of life, resolution ofcomorbidities, food tolerance, and 6-year weight loss. SurgEndosc 2011;25:2498-2504.

26. Gagner M, Hutchinson C, Rosenthal R. Fifth International Consensus Conference: current status of sleeve gastrectomy. SurgObesRelat Dis. 2016 May;12(4):750-756. doi: 10.1016/j.soard.2016.01.022. Epub 2016 Jan 25. PMID: 27178618 